Wurtz-Chemical and Sumitary Rejort upon Passaic River. is struction per cubic foot, is given. The only data I ean obtuin from foreigu reports on either of these points, is from one on the bublin and Drogheda R. R.; and I deduce from this data, that the creosoting of the ties costs six cents per cubic foot of timber with seven pounds of "crude" oil per cubic foot. Without all the items just mentioned, it is impossible to solve the problem of the measure of the economy of creosoting in fureign countries.

Mr. Page, whose report bears date $2 x t h$ May, 1870, male the subject of a specialty recently in European countries. IIe says, that " the creosoted timber for railroad constructions has not yet failed from perfect soundncis. * * * Wood for marine constructions, railroad constructions, fences, telegraph and hop poles, and for uses in coal and iron mines, is almost universally creosoted; and that treated timber is the rule; and nutreated timber the exception. * * Another effect is observed; iron spikes, nails, bolts, etc., inserted in creosoted wood are protected effectually from rust. * * * And crude creosote oil is almost universally used in the process all over Europe."

(To he cuntinuenl.)

\title{
CHEMICAL AND SANITARY REPORT UPON THE PASSAIC RIVER.
}

Made to the Board of Public Works of Jersey City.

By Professor ll herr Wurtz.

(Abstract. made and communicated to this Journal, by the Author.)

HoßоKes, March 1st, 1873.

GEXTLEME, - I have been charged by your Jlonorable Board with the investigation of the waters of the Passaic, with a view to determine the sanitury questions regarding contamination by sewage and other causes.

All the analytical results herein reported were obtained by the personal labor of the undersigned.

Collection of the Samples for Analyxis.--At the outset of the investigation, and on his first visit to your Pumping Works at Belleville, your reporter recognized a source of contamination to the stream which has hitherto been strangely overlooked. It seems incredible that it should be pointed out for the first time here; but, in a sanitary view, it clearly involves the most important questions connected with this stream, and its relations to the rapidly increasing town populations that look thereto for their supply of a necessary of life. 
The source of contamination referred to is the flow in to your pumps, during rising tides at least, of water which must have received tho drainage of the populous city of Newark.

Samples were therefore so collected at Belleville as to enable this new question-regarded as the most important one that has arisento be tested analytically; namely, by taking the water at extreme bigh tide, to represent the maximum of contamination from Newark : as well as at extreme low tide, to represent water contaminated only with matters bronght down by the river itself and its affluents above Belleville. An additional sample was taken from the Receiving Reservoir.

It providentially happened that it was possible to procure these samples after an interval of dry atmosphere, of at least eight days. (October the 10th, 1872, being the date); thus giving us the important assurance of absence of dilution of the river with rin. Since then there has been no occasion equally favorable; the incessant and almest unexampled alternations of rains, snows and thaws, having kept up in the river a continual condition, mole or less, of flood. Samples were afterwards obtained from above the Passaic Falls, from the discharge of two of the main sewers of Paterson, and from the river itself below the discharge of all the sewers of importance, off the Straight Street Bridge, Paterson.

In connection with the sewers, other instructions received from your Honorable Board were, as far as practicable, carried out, relating to inquiries in to sources of possible. contamination of the sewage waters by mineral and metallic matters, from the different dye works. and factories.

The samples were sealed securely, with pure paraffin, at the water works (in the presence of your Chief Engineer, Mr. Culver), and after being packed in an inverted position, were transported to the laboratory of the writer in Hobok (n).

Preliminary Preparation of the Samples.-The bottles were placed, without unsealing, in a light room without fire, which, because surrounded by other rooms constantly warmed, remained above freezing even during the intensity of the past winter. The primary object was to obtain such sediments as might deposit, including possible products of germination and growth of vegetable spores. In about one month (November 14th), the samples of water, having then become perfectly limpid, though of a pale brownish tint, were carefully pipet- 
ted off from the sediments, the latter collected, dried at an extremely gentle heat, weighed, and reserved for examinntion as below.

The Methods of Analysis. - The oller methods of analysis of potable waters, by which it las been customary to determine with great precision the actual quantities and relative proportions, per stated volume, of all the different acids and bases belonging to the purely "inorganic" constituents, bave, within a decade past, fallen into disrepute and even desuetude among some chemists who have been active in the advancement of sanitary chemistry; and a far greater importance now attaches, among these. to the so-called "organic" constituents, or rather those assumed to be peculiarly of organic origin. This later school of chemists and sanitarians has in many cases abandoned the practice of determining anything regarding the solid socalled "mineral constitucints" more than their simple sum total, after expelling all volatile matter."

Tinere is, on the other haml. another sclush of water-analysta, which adberes to older ideas, and, as the writer believes, exaggerates much the difficulties and uncertainties its adhorents attach to most of the more recent methods of detecting and determining constituents present in quantities too small to be weighed-a class of constituents comprising inany of the products of putrefaction and deeay. This school goes so far in the other direction, as to reject the modern "microchemical " methods, as of no practical value.

From this conclusion, and from the general views of both the schools of chemists referred to, the present writer's own experience forces him to dissent; and, in brief, his own belief rests on the middle ground between these two schools: and, in this investigation, he has deemed it essential to apply, as thoroughly as possible, both the older and newer schemes of analysis.

Special Observations on Methold. - The residues left by all the sam. ples of water on evaporation in white porcelain, were of an orange buff, approaching to salmon-color, while those left in platinum dishes were gray in color; and all, on heating, turned black, with a strong "peaty" odor, or at least an odor recalling strongly that of peat smoke. This odor, however, is of little value in itself as an indication of the character of the volatile matter present; but subsequent tests proved the presence of one or wore of the peaty acids. The

* The highly valnable manual on Water-Analysis, by Wanklyn and Chap. man, is an example of this, and I fear has done much harm in this direction. 
incineration was very difficult, more like that of animal matters; and at the point of temperature required to form a white ash, a slight fume was often seen, though ton slight to allow its character to be determined. 'The ash was nearly white, and effervesed slightly with ncids, dissolvine in muriatic with a distinctly yellow color, indicative of iron.

In addition to the simples from Belleville, it was thought important to take the opportunity to ulitain the average composition of the water for tho wintur months, just as delivered and used by cumsumers, sediment and all, firm the service pipes in lloboken. In one case, during twenty days, as much as twonty quarts of the water were concentrated in a platinum dish on a water-bath, the object in this particular case, as well as in one other, having been to determine the ammonia, a drop of sulphuic acid being therefore added at the outset. It is to be remembered that these results on the hydrant water creported in the fourth columus of the two tables of analyses griven below). relate to an unusual winter periol, during which the stream was more or less in continual flomil.

Within a few years some European analysts have been active in devising new methols of discovering and determiniug substances which, though often ocentring in waters in proportions justly termed microchemical, are meverteless widely believed now to be of vital importance in a hygienic view.

It appears appropriate and requisite that a few specific though brief paragraphs (which may be more especially interesting, nevertheless, to readers of chemical attainments) should be given to an enumeration at least of the following mothods, which were submitted to preliminary examination, and some of which were since made good use of in this risearcht.

The Forchhammer-Condy l'ermanganate method: with the modifcations recommended by Angus Smith, in whose high opinions of the real value of this method, when used understandingly, the writer must largely concur, though he has spent comparatively little time in actual work with it.

The Nessler. Iladow method for ammonia; which, as all chemists now familiarly know, is beyond all price or appreciation, in all chem ical analysis, that for sanitary purposes included. To illustrate the extraordinary value of this Nessler-Hadow micro-chemical method, and the encrmous stride in advance marked by it, it may here be added that in the cvaporation before referred to, of twenty quarts of 
Wertz-Chemient and Sanitury lequrt upon P'assaic Riter. 57

hydrant water with acid, occupying twenty days, an attempt made to determine ammonia in the residuum, by common alkalimetry, failed altogether. In another parallel experiment, however, involving considerably less time and material, no less than five well-concurrent determinations were made uponthe result of distillation with alkali, and three times as inany more might have been had. The average figure arrived at is given below-0.005 grain of ammonia per gallon. The failure of the ordinary volumetrie methods is here clear enough when we consider that the whole five gallons concentinted contrined but one fortieth of a grain of ammonia.

The method for nitrogen acids, founded on reduction to ammonia by a metal, and then the Nessler-Hadow methorl. Schulze's improve. ment of using metallic aluminum in alkaline solutions, was found valuable; but the writer has founl it far preferable to use, in addition, clipped iron wire, which, while hastening the operation by voltaic action, also subsequently prevents explosive ebullition, and bursting of the retorts. [It may convey to your IIonorable Board some ide of ane of the difficulties of this kind of investigation, to add that each repetition of the determinations of nitric acid here reported, and they were many, required alone at latst one day of hard and anxious work and watching, and that before the diseovery of the above safeguard, a dangerous explosion, involving damage to property, had occurred.]

The volumetric method for the atermination of chlorine, with standard solution of silver and chromate of potash; which has been so highly lawded by some chemists, fitiled altogether in the hands of the writer, and he hand to abandon it.

The Alkaline Pertranganate methud, for "albumetoids" or Proteine bodies of Wanklyu and Chipman. This method, which is less understood, probably, than any of the other's mentioncd, has been tested with some care: at first with the unsatisfactory results reported by some other chemists, and at last with some degree of satisfaction. Details cannot be entered into here. It is certain that $W$, and $C$. proved the existence of some form of nitrogenous matter in potable waters (previously freed from amuonia), which is convertible intu additional ammonia (at least in part) by distillation with their new reagent. They also show similar results with albuminous matters, and with the usual immediate products of their metamorphoses, and it is hard to see what other substances could get into fluviatile and many other waters, that could give ammonia in this way. It is on these grounds that the writer has provisionally accepted their views and 
their methods, and put the results int his talles of analyical results. As Dr. Angus Smith prefers the term proteine to albumen, in this case, it has been used here also. As the rule of Wanklyn and Chapman is to consider ammonia thus found to represent ten times as much "albumenoid," the figures in the table stand for but one tenth as much aminonia.

New Tests of Oxygenation and Rate of Aeration.-The writer has the satisfaction to announce here that, in the progress of this work, he has found new and valuable microchemical tests for potable waters, as to both the existing degree of aeration (or impregnation with free oxygen) and the rate of absorption of aerial oxygen; which he believes will be of especial value in determining the questions that have arisen regarding the Passaic water. Eminent chemists and sanitarians are agreed upon the important bearing of this ingredient (free oxygen) in potable waters. It has been considered as furmishing a measure of the freedom from liability to undergo fermentation or putrefaction: and it will scarce be denied by any that the most highly aerated water is, ceteris paribus. the safest. Oxygun is a consumer and destroyer, and in water destroys the enemic so human life therein. Indeed, it is too often the destroyer of hunan life itself, but with that we have now nothing to do. Streams flow through an atmosphere containing one-fifth of oxygen, but their preeise actual contents, and their relative tendency to absorb, and their actual absorption of this agent (which latter is regarded as the measure of their ability to parify themselves), have heretofore been little more than matters of pure guesswork or conjecture. A reasoniable hope may now be held that all this will soon be changed. T'wo or three of the curious and unexpected results of this new method may be mentioned.

Sewage which smells offensively of sulphuretted hydrogen still retains free oxygen, in traces readily indicated by this test.

Water may be boiled indefinitely. even boiled away altogether, but retain to the last traces of free oxygen.

Common salt expels all the oxygen from water (with certain precautions); the true explanation of its preservative power, etc., etc.

The Analyses.-All these figures are calculated on the basis of one United States gallon equalling 231 cubic inches of distilled water, pach cubic inch weighing at $60^{\circ}$ Fahr. $252 \cdot 5$ grains, making that gallon $58, \hat{3} 27 \cdot 5$ grains. Some estimate it at a slightly different figure. but the difference is so trifling as to be immaterial. 
Wurtz-Chemical and Sanitary Report upon Passaic River. 59

Immediate Results of Analyses of Samples of the Passaic Water, expressed in grains and fractions thereof, per U. S. gallon of $58,327 \cdot 5$ grains.

\begin{tabular}{|c|c|c|c|c|}
\hline \multirow{2}{*}{$\begin{array}{l}\text { Constituents of the } \\
\text { Residues } \\
\text { from Evaporation. }\end{array}$} & \multicolumn{3}{|c|}{$\begin{array}{l}\text { Settled Waters, taken Octob } r \quad 10 \\
1872 \text {, at Belleville. }\end{array}$} & \multirow{2}{*}{$\begin{array}{l}\text { Analysis of } 5 \text { gals. of } \\
\text { Unsettled Water, tak- } \\
\text { en day hy day from } \\
\text { Hydrant in Hoboken. } \\
\text { Winter average, De } \\
\text { cember and January. }\end{array}$} \\
\hline & $\begin{array}{l}\text { Extreme } \\
\text { Low Tide. }\end{array}$ & $\begin{array}{c}\text { Extreme } \\
\text { High Tide. }\end{array}$ & $\begin{array}{l}\text { Recejving } \\
\text { Reservoir. }\end{array}$ & \\
\hline 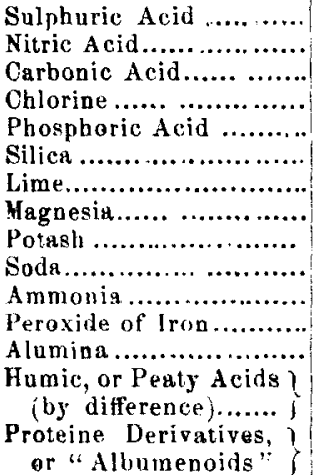 & $\begin{array}{r}6461 \\
\cdot 1925 \\
.4100 \\
\cdot 1505 \\
.3800 \\
.7910 \\
1.0400 \\
.3580 \\
.0487 \\
.1857 \\
.0109 \\
.1170 \\
\cdot 1660 \\
.6007\end{array}$ & $\begin{array}{r}-7760 \\
\cdot 3383 \\
.2006 \\
.2923 \\
\cdot 1780 \\
\cdot 1120 \\
1 \cdot 1974 \\
\cdot 4930 \\
\cdot 2500 \\
.4200 \\
.0038 \\
.0562 \\
.0956 \\
.2038\end{array}$ & $\begin{array}{r}.6500 \\
.2409 \\
.2500 \\
.2163 \\
.2001 \\
.4000 \\
1 \cdot 1120 \\
.4100 \\
.2375 \\
.3840 \\
.0088 \\
.0830 \\
\cdot 1322 \\
.3612\end{array}$ & $\begin{array}{l}\cdot 2012 \\
\cdot 2800 \\
\cdot 2880 \\
\cdot 1520 \\
\cdot 1202 \\
\cdot 6344 \\
\cdot 8037 \\
-3950 \\
\cdot 1375 \\
\cdot 2730 \\
\cdot 0050 \\
\cdot 0699 \\
\cdot 0868 \\
\cdot 6136\end{array}$ \\
\hline & $5 \cdot 1900$ & 4.6830 & 47670 & $4 \cdot 1070$ \\
\hline
\end{tabular}

It will be observed that the amounts of volatile and combustible matter are not given, as is usual (these being duly classed as "organic matter"). In the case of this water, these are in large measure made up of nitric acid, carbonic acid expelled by the silica, and oxygen from the coaversion of the sulphates into sulphides.

The Sediments.-Before the settled water was pipetted off from the sediment, in each case, a mark was made on the bottle at the surface of the liquid. The sediments were carefully detached from the glass in every part by bent rubber-tipped glass rods, washed with some of the same water into small beakers, from which, after settling again clear, they were transferred to weighed watch-crystals, dried at about $100^{\circ}$ Fahrenheit, and weighed. The volume and weight of the water were then found by filling up to the mark from a calibrated measuring-cylinter. 
Histimate's of the Dissolved Saline Contents of I'ussaic Waters; fizmle. on Analyses; expressed in grains and frotions thereof, per $l ., S$ gallon of $58,327 \cdot 5$ grain.

\begin{tabular}{|c|c|c|c|c|c|}
\hline \multirow{2}{*}{$\begin{array}{l}\text { Theoretical Constituent } \\
\text { of the Residue } \\
\text { from Eraporation. }\end{array}$} & \multicolumn{3}{|c|}{$\begin{array}{l}\text { Samples taken at Pelleville, Oct. } \\
\text { loth, I8T2. Thoromghly getted } \\
\text { before Analysis. }\end{array}$} & \multirow{2}{*}{ 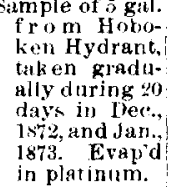 } & \multirow{2}{*}{  } \\
\hline & $\begin{array}{l}\text { Extreme } \\
\text { Low Tide. }\end{array}$ & $\begin{array}{c}\text { Fxtreme } \\
\text { nigh Tith. }\end{array}$ & $\begin{array}{l}\text { Recteiving } \\
\text { Reservoir. }\end{array}$ & & \\
\hline Sulp & 1.09885 & $1 \cdot 3192$ & $1 \cdot 1050$ & $.3+20$ & \\
\hline Nitrate of Lime... & $\cdot 2923$ & $513 i$ & 3288 & .4253 & \\
\hline $\begin{array}{c}\text { Phosphate of lime- } \\
\text { tribatic. }\end{array}$ & 8300 & $\because 8+i$ & 4368 & $\because 624$ & \\
\hline Carbonate of Lime......... & .0672 & $+54 i$ & .54881 & $6 \hat{5}+5$ & \\
\hline $\begin{array}{l}\text { Carbonate of Hagnesia . } \\
\text { Chloride of Sodiam ..... }\end{array}$ & $\begin{array}{l}\cdot .25 \% \\
.24819\end{array}$ & .4817 & $356+$ & 2305 & \pm \\
\hline 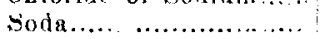 & 11911 & -1652 & $.199 ;$ & .1402 & \\
\hline Potash .............. & $\therefore 1190$ & $\cdot 2500$ & $28: 5$ & $\cdot 1575$ & \\
\hline Magnesia.................... & -0124 & $\cdot 4: 30$ & 4100 & 3950 & \\
\hline Ling & - & .0158 & 0143 & $.00(196)$ & \\
\hline $\begin{array}{l}\text { Silica } \\
\text { Hrdeated Peroxide ot" }\end{array}$ & -7194 & -1120 & $\cdot \$ 001)$ & $.6 i 34+i$ & \\
\hline $\begin{array}{l}\text { Hydtated Peroxide ot' } \\
\text { Iron... ...................... }\end{array}$ & - 1:285 & $0.65 i$ & .0970 & $.0 \times 17$ & \\
\hline Hydrate of Alumina...... & -2530 & 1458 & 2015 & -1323 & \\
\hline $\left.\begin{array}{c}\text { Humic or Peaty Lcids } \\
\text { by difference } . . . . .\end{array}\right\}$ & 6000 & 2638 & 3012 & -61306 & \\
\hline $\begin{array}{l}\text { Ammonia, free and com- } \\
\text { bined for ts Ureal..... }\end{array}$ & $\{-0100$ & .0058 & $-008 s$ & .11050 & \\
\hline $\begin{array}{l}\text { Proteine Derivatives, or } \\
\text { "Albumenoid"matters }\end{array}$ & $f .043 i$ & $-16+6$ & $.0 \times 10$ & $\cdot 0445$ & \\
\hline $\begin{array}{l}\text { Total Grains pex } \\
\text { gallon ................... }\end{array}$ & $5 \cdot 27+66$ & +7906 & $+806 i$ & $4 \cdot 1300$ & \\
\hline
\end{tabular}

Sedimentary Deposits.

\begin{tabular}{|c|c|c|c|c|}
\hline WATERS. &  & 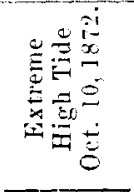 & 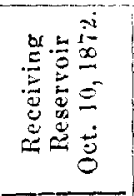 & 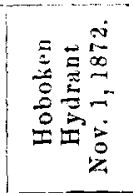 \\
\hline $\begin{array}{l}\text { Amounts operated on, in grains, } \\
\text { Grains found, per U. S. gallon, } \\
\text { Prof. Horsford, October, } 1851 \text {, } \\
\text { Prof. Chandler, Hoboken Hy- } \\
\text { drant water of May } 3,1872 \\
\text { Total solid contents of unset- } \\
\text { tled waters; that is, the sum } \\
\text { of these sediments and resi- } \\
\text { dues of evaporation, }\end{array}$ & $\begin{array}{r}61.729 \\
1.008\end{array}$ & $\begin{array}{r}62.470 \\
0.504 \\
1.262\end{array}$ & $\begin{array}{r}60.186 \\
0.479\end{array}$ & $\begin{array}{r}58.327 \\
0.493 \\
0.520\end{array}$ \\
\hline
\end{tabular}


In the low tide water and receiving reservoir, appeared quantities of a green confervoil growth, characteristic of standing waters, mach more perceptible on the watch erystal during dessication than at any time before. There was more of it in the low tide water. In the high tide sediment there was wot the slightest trace of this perceptible to the eye.

Hicroscopie Fixaminations. -The generin results of these were confirmatory of the above. The low-tide sediment was apparently made up chiefly of beautiful spicular and fibrous organisms, with bunches of their spores, doubtless belonging to the conterve (fresh water algo, frog-spittle). These were mingled with very minute translucent grains, looking like rounded sand, but more prubably clay. In the reservoir sediment, there was more of the sandy looking matter and less of the organisms. Curious to say, however, though the search was made patiently for a long tine, no trace of fibre or spore or anything organized whatever, appeared in the high-tile sediment. It was all a fine sandy looking mud. As all these waters hal been kept under precisely identical conditions, and us the germs of this vegetation must have been equally dispersed through all of them, this is regarded as a most surprising fact. That the Newark sewage, or some other influence removes, between low and high tide, from the water, something essential to the germination and growth of regetation, or else imparts something inimical thereto, are the only inferences to be drawn. Some of the green mass of confervoid fibre, removed from the edge of the watch crystal, of the low-tide sediment, and burned to ash on plati. num foil, left a voluminous mass of white spiculse, which, transferred to a platinum loop, fused readily to a transparent glass, and behaved generully like a mass of phosphates, but the quantity was too small for analysis. An attempt wis made to determine, by incinerating, the amount of vegetable matter in the two sediments containing it, assuming that the mineral portion of each retained, when dried in air, about the same amount of water. The following are the results:

\begin{tabular}{|c|c|c|c|}
\hline & $\begin{array}{l}\text { Water per } 100 \text { af } \\
\text { Sediment. } \\
\text { (Estimated for } \\
3 \text { and } 4 \text { ) }\end{array}$ & $\begin{array}{l}\text { Anhydreus } \\
\text { Mineral natt } r \text {, } \\
\text { per U. S. gallon } \\
\text { of water. }\end{array}$ & $\begin{array}{l}\text { Vegetable Glowth, in one } \\
\text { U.S. gallon, in dry form. }\end{array}$ \\
\hline $\begin{array}{l}\text { 1. High Tide, } \\
\text { 2. Hydrant, } \\
\text { 3. Low Tide, } \\
\text { 4. Reservoir, }\end{array}$ & $\begin{array}{r}20 \cdot 00 \\
23 \cdot 38 \\
8 \cdot 32 \\
15 \cdot 01\end{array}$ & $\begin{array}{l}0.403 \text { grain, } \\
0368 \text { ، } \\
0.349 \\
0.255\end{array}$ & $\begin{array}{c}\text { None. } \\
\text { (not determined) } \\
0.561 \text { grain. } \\
0.152\end{array}$ \\
\hline
\end{tabular}


The results in the last column of this little table must be regard as among the most interesting obtained in the course of this invest gation. The ash in each case contained iron, and had apparent about the same tinge of red.

Chemical and Sanitary Discussion of the Analyses. - These analy. ses furnish many points of interest in a purely chemical view, but il would be inappropriate to give much space to any of these, which have no direct sanitary bearing. Among the most important are th: changes incurred by the water while being swept backward and for. ward past Newark by the tides. These are (see Table II) :

A small increase of sulphuric acid, lime and magnesia.

A large increase of the nitric acid, chlorine, soda and proteine de.. rivatives.

A diminution of the carbonic acid, phosphoric acid, iron, alumina and humus compounds.

A large diminution of the silica.

The increase of nitric acid accounts for a large part (say half) the loss of carbonic acid. The phosphoric acid may very well be be. lieved to have gone down with the alumina and iron, taking with it humus and some ammonia, and if, as seems probable, the silica it really held in solution by the humus acids, this would precipitats also. The loss of these ingredients possibly accounts for the fact that no confervoid growth whatever appeared in the bottle of high. tide water, as stated under the head of sediments.

Among these chemical points, of sanitary bearing, doubtless the most striking and important of all is the increase in the quantity o: nitric acid in the water brought up by the rising tide past Newark. which increase is $\mathbf{1 4 5 8}$ grain per gallon. If this is regarded as having proceeded from albuminous or proteine bodies, it represents: .923 grain of these, which, added to the increase in the quantity of such bodies found directly, makes 986 , for simplicity say one grain per gallon, of dry products of putrefaction of albuminous matters, or say equivalent to 4 grains of decomposing egg-albumen per gallon.

If we suppose one rotten egg, weighing about 800 grains, to be beaten up with 200 gallons of low-tide water at Belleville, it might represent the initial effect of the Newark sewage, according to this rather unsavory calculation. What a rapid change is here shown to have occurred during the short run that the water has had, only be- 
tween three and four miles, from New York up to Belleville.* The sewage inatters have been constantly suffering a process of decay, slow combustion, or eremacausis (as it was called by Liebig), through the agency of the free oxygen held in solution in the highly aeruted water pouring in every day from up stream; and, as the analyses further show, the residuum of the albumen or proteine derivatives, left from the Newark sewage, uver and above those brought down from up stream, is but .063 grain per gallon, and the whole amount in the high-tide but about one-tenth of a grain, equivalent, if putrid, to one rotten egg in 2,000 gallons of water. But it is unreasonable to suppose that this substance, whatever it may be, which yields am. monia with the powerful reagent of Wanklyn \& Chapman, is still in a state of putrefactive change, or even capable of such change. Proteine bodies yield many products of metamorphosis which are highly stable. Dr. R. Angus Smith, in his writings on these subjects, refers repeatedly to waters answering to the Wanklyn-Chapman test, which are nevertheless incapable of putrefaction, and in one place infers the existence of some proteine body not susceptible of this change. $t$

The agency which effects this change, between Newark and Belleville, is that universal one which has long been studied by chemists, known as nitrification. Animal matters containing nitrogen, with water, oxygen, alkaline substances, and always time, are the conditions requisite to its progress. These analyses show the Passaic water to be an alkaline water, and we have present all the conditions for nitrification. The surprising circumstance is the short time apparently required.

The 3383 grain of nitric acid in the high-tide water represents, when calculated as saltpetre, 6327 grain thereof, and this, when calculated on the average daily flow of the Passaic water, is 90,400 lbs. of saltpetre per day (about 16,500 tons per year). About 40,000 Ibs. per day of this is furnished by Newark, the other 50,000 by the rest of the inhabitants, both man and beast, oppidan and rural, of the 900 square miles of Passaic water-shed above. When we remember that this nitric acid represents but a fraction of the nitrogen of the effete matter from which it came, and that this nitrogen was itself

* On further consideration, since writing the above, it appears probable, however, that much of the water brought up by the high tides has run past Newark, back and forth, several times, and has had therefore a far longer course of flow than this. Still the average result should be the same. H. W.

† Chemical News, June 11, 1869, page 281. 
hut a small percentage of the whole, it is clear that these thousan. of pounds of saltpetre must represent hundreds of thousands of poum of effete matter cast daily into the waters of the Passaic. Some er nent chemists, particularly in England, have thrown doubts upon t conclusions drawn by others from nitrates, as indicating previor sewage contamination; claiming that nitrates may be washed cut . older geological formations, and so or. In our present investigatio we may cast aside this objection, as the Passaic basin contains not ing of the sort that could yield nitrates. All these must have com: from the excretia of men and animals, the washings of barnyard. manured soils, etc.

We bave now considered the bright side of the picture: let us loo on the reverse. These samples of water were collected in cool at tumn weather. Would analyses of the water in the heat of the sum mer show the same or like results, when the water is warm? Th warmer the water, the less oxygen it an absorb under given circun stances. It is the oxygen dissolved in the water that does the work and not that of the circumambient air, which can act but superficially

In 18.57 , the great chemist, Bansen, ${ }^{*}$ published deterninations o the capability of water to absorb oxygen at different temperatures The following figures are extracted from his tables. One hundrec volumes of water, when saturated with oxygen, contain at the temper. atures specified respectively (reduced to Fahrenheit degrees, the in tervals being $\dot{\sigma}^{\circ}\left(\therefore\right.$ or $9^{\circ} \mathrm{F}$. apart) :

At \begin{tabular}{l|l|l|l|l|l}
$32^{\circ}$ (ficezing) & $41^{\circ}$ & $50^{\circ}$ & $59^{\circ}$ & $68^{\circ}$ & \\
$4 \cdot 12$ & 3.63 & $3 \cdot 25$ & 2.99 & $2 \cdot 84$ & volumes. \\
\hline
\end{tabular}

As the temperature of the water during the summer heats ranges ten or fifteen degrees higher than the last figure (which is as high as Bunsen gave), we may assume as approximate that the power of the same water to absorb oxygen, ceteris paribus, is twice as great in the winter cold as in the summer heat. The qualification is used, because barometric pressure, and composition of the water itself, particularly the latter circumstance, have large, and even overwhelming influence, as has been ascertained by cxperiments with the new methods before referred to. 
In addition to this momentous fact, that water can absorb at the utmost but half as much oxygen per gallon in summer as in winter, another fact, also important it may be, must be remembered. The volume of aerated water that flows down from above tide-water in the former season, is far less than at other seasons. There are no means of exactly determining the difference at present at hand, except by comparison with other rivers in nearly the same latitude. The difference, for instance, between the maximum flow of the Hudson at Albany in March, and its minimum in July, is as seven to one! If this rule holds as to the Passaic, the amount of oxygen brought down by the stream, to attack and destroy the fæcal and urinary compounds cast into the river at Newark, is in July but one-fourteenth as great as during the flooded seasons. 'This, however, is doubtless too strong a view, as the alternate sweep of the stream up and down at each tidal change, even to some extent as far up as the Dundee dam, some seven miles above Belleville,* must assist largely in the aerating operation, and this operation is therefore by no means wholly dependent on the down-flow of the river itself. Still, when we consider that in midsummer the heat intensifies putrefaction, and that the amount of available oxygen to destroy its products is largely diminished by the enfeebled solubility of oxygen in the water, it would appear that we have a reasonable solution of the unpleasant odor and taste that the water has of late years sometimes acquired in July. $\dagger$

Moreover, looking to the future, though there seems every reason, on considering these analyses, to believe that no detriment to the public health has up to this time arisen from the use of these waters, there seems to be no good reason to deduce the slightest confidence or belief in an indefinite, or even a long continuation of this immunity. Newark grows rapidly, and grows towards Belleville; and the distance from your pumps within whick it is safe to have a common sewer emptying into your river has not yet been determined.

Remarks upon Aeration of Potable Waters. - It will probably not be expected that space should be occupied with authorities, quoted in support of the proposition, that a necessary condition of a healthy

* I was informed at Belleville that the tides there average 5 and 12 feet, and are three-quarters of an hour later than at New York.

H. W.

$\dagger$ I was told by a leading butcher of Hoboken, a reliable man, that be did not dare to use the hydrant water in the summer season to wash his meat, as it quickly turned the latter green; a fact which did not hold when well water was ased.

H. W.

VoL. LXVI.-ThI8d Srrina.-No. 1.-Joux, 1873. 
water is good aeration. The universal experience of mankind has taught them this. A well or an underground cistern may be deprived of light (indeed the less light the better), but air it must have, or it putrefies in spite of all.

Dr. Letheby has recently produced facts to show that the deathrates of British towns are proportional to the absence of the earthy bases from the water supply; and has argued that these bases are needed for the making of blood, bones, etc. His facts are undeniable, but the present writer has a very different explanation to suggest, namely, that these bases are needed by oxygen in its work of nitrification and destruction of putrefactive matter, an explanation which seems far more satisfactory.

Early in this investigation, when your reporter first began to see the nature of the process going on in the Passaic waters, the immediate necessity forced itself upon him of possessing reliable methods of determining the amount and rate of aeration of water. On trying the methods heretofore in use, they were found far from reliable or delicate enough for the purposes required. He therefore cast about him for new means, and in the course of time and experiment settled upon a reagent introduced long since by Liebig, for deterwining oxygen in the air, and widely used in gas analysis, called pyrogallic acid. (As it is not an acid, it is preferable to follow some of the English chemists, and call it pyrogalline.) The details of the methods that have been founded on the use of this agent in water analysis must be reserved for communication to the chemical world in another form. Great difficulties were met with in the practical application, but have been satisfactorily overcome. It furnishes now the means not only of determining the amount of oxygen already existing in the water, but also of determining the rate of its absorption by different waters, and under different circumstances.

Considerations in reference to new sources of water supply, or new modes of supply, are not within the province of this Report; but it may be considered as pertinent for your reporter to submit to your. Board any views lonking towards improvements of, and making the best of, the present supply and mode of supply; premising, however, with emphasis, that these are only intended to be regarded as suggestions, which, by awakening attention to the subject, may possibly give rise to far better and more practicable plans.

Now, that we are acquainted with the nature of the wonderful process of regeneration and revivitication that goes on in our water, it 
The Passaic Water-Shed.*-Not being able to find any data for the computation of the flow of the Passaic River, it was determined to make a careful measurement of its water-shed or basin, which was accomplished by the method of weighing.

Three sections of the large geological map of the State were found, on being pieced together carefully, to cover all but a very trifling corner of the water-shed, at the head-waters of the Saddle River. The wonderfully tortuous rim of the basin was now very carefully traced out all round, following a medial line between the heads of the small tributaries and those of the adjoining basins, using a soft pencil. Tracing muslin of the best quality was now superposed, and the former line followed round again. Small sharp scissors were now called into requisition, the water-shed cut out, carefully rolled up, and weighed on a delicate chemical balance. 120 square inches of the same muslin were then carefully measured out, cut out in the sume way and also weighed. As the scale of the map is two miles to the inch, this represents 480 square miles. The weight of this and of the whole water-shed being known, it becomes a simple rule-ofthree sum.

Two such maps were made. One, on which I endeavored roughly to trace out the river and its main tributaries, I present herewith, that you may be enabled to inspect the form of this singular basin. On the other were traced out, before detaching it, the boundaries of the different geological formations that are included within the basin, also the State line between New Jersey and New York. This latter map was dissected, and weighed piecemeal, to determine these different areas.

The following are the figures obtained:

Area of Passaic Water-Shed, . . . 908 sq. miles. Area of the New York portion thereof, . . 148.5 " Area of the Crystalline Rocks of the Highlands, within the Water-Shed, . . . . 4 484.5 " Area of the Brown "Sandstone," and Trap ('Triassic) formations, . . . . . . . . . 4 4 423.5

[It was the original intention to enter into some geological, or rather lithological discussion, based on these measurements, and the bearing of the results of the analyses upon the composition of the rocks, the more especially as your reporter has spent much of his life

- A chapter containing a discussion of former examinations of Passaic water is omitted in this abstract.-ED. 
in the study of the rocks, minerals and general geology of northern New Jersey. It was intended to calculate the rainfall in the basin for each month in the year, and other interesting matters besides; but it is now feared that the necessary limits of this report would be sorpassed.]

The water-shed of the Passaic, it thus appears, is much larger thau had been anticipated, and it is evident that the estimates beretofore accepted, of the average flow of this stream, are greatly below the truth. The annual rainfall is known to be more than 50 inches,* and a simple calculation shows, therefore, that the total amount of water received by the Passaic and its tributaries in one year, is 782,100 ,000,000 gallons, or $2,115,000,000$ gallons per day, on an average. As it is usual to allow a loss of one-half, however; by evaporation, it will be safe to call the average daily flow of the Passasc one thousand million gallons. This is" not much less than the average assigned to the river Thames, $1,350,000,000$ gallons; although that river is more than 250 miles long and ours but 80 miles. This fact serves to illustrate the very remarkable character of the Passaic basin. The rainfall, however, in the Thames valley is but 27 inches. The Croton water-shed measures 339 square miles, so that our water-shed is $2 \cdot T$ times the size of that which supplies New York City. Nine-tenths of this water-shed lies above Paterson, and its drainage flows over the falls at that place. We have water enough (with reservoirs of sufficient capacity and in proper locations) for all our cities for centuries to come, not only for domestic, steam and manufacturing uses, but even for water-power, where small powers are required (as for stwing-machines, for example). The problem is, how to make it come to our cities without constantly augmenting cost. This, however, is a matter outside the scope of the present report.

The Sewage of Paterson.-Included in the instructions upon which this investigation was based, were examinations into the question that hits caused alarm to some, whether the Passaic water is not possibly contaminated, and rendered poisonous, discharged from the dye-works, and other works in which chemicals are employed, in Paterson.

* The mean annual rainfalls were, for a series of years:

For Newark,

For Paterson,

For Dover,

Mean, 
It is among chemists an accepted fact, that no such substances are thrown by manufacturing cities into rivers, in any permanent form of solution; but, as many who use our water would be much better satisfied with direct chemical evidence on this head, as much time was spent in these examinations as could be reasonably taken from things of greater profit, visits were made to a number of these works, and it was ascertained that there was a possibility of small quantities of waste lead and copper solutions finding their way into the drains. The aniline colors, some of which, it has been suggested, might carry arsenic into the river, were stated to be too costly to allow of any waste. They are always used up entirely. It has been stated on a previous page that samples were taken from two of the main sewers, and from the river below all the sewers at the Straight Street Bridge. All these, though kept in a room without fire, tightly stoppered, and in very cold weather, began straightway to putrefy, and to evolve free sulphuretted hydrogen. As neither lead, copper nor arsenic cain remain in solution for a moment in water containing sulphuretted hydrogen, this was pretty conclusive; yet it was deemed best to make it crucial experiment. To a portion of each water was added small quantities of solutions of lead, copper and arsenic. After settling for twenty-four hours, the filtered liquids were rigidly tested, and no trace of either of these three metals could be found left in solution.

It should be added, for the behoof of chemists, that all these samples were absolutely neutral to test papers; a somewhat surprising fiact, when it is stated that the samples were collected on a washing day (Tuesday, from $2 \cdot 30$ to $3 \cdot 30$ P. $\mathrm{M}$.), and it was expected that thry would be perceptibly affected by the alkali of the soap. The amount of sediments deposited by these samples respectively, after rtanding at rest one month, were as follows:

\begin{tabular}{|c|c|c|}
\hline WATER. & Quantity omployed. & $\begin{array}{l}\text { Grains of dry sedi- } \\
\text { ment per C.S. gal- } \\
\text { low. }\end{array}$ \\
\hline $\begin{array}{l}\text { River, from Straight St. bridge, } \\
\text { Prospect Street sewer, . } \\
\text { l'aterson Street sewer, . }\end{array}$ & $\begin{array}{cc}530 & \text { grammes. } \\
578 & 6 \\
680 & 6\end{array}$ & $\begin{array}{r}1 \cdot 101 \\
2 \cdot 119 \\
10 \cdot 19+\end{array}$ \\
\hline
\end{tabular}

It had been intended to report other analytical results obtained in connection with the sewers, but as the above comprise all that have any obvious sanitary bearing, it is judged better not to swell the report with them. 
Some microscopic observations were made on the above sediments, but nothing observed of much interest, except the somewhat curious fact that the river water taken from the Straight Street Bridge gave a sediment singularly crowded with fragments of fibres of various kinds, derived apparently from different textile tissues.

Summary-1. The basin drained by the Passaic River contains over 900 square miles of territory, and receives annually over 782,$000,000,000$, or, as daily average, over $2,100,000,000$ of gallons of water.

2. Allowing an average loss of one-half by evaporation (doubtless an over-estimate), the annual flow of the river at Newark is 390,000 ,000,000 gallons.

3. The actual daily flow varies within wide limits, as yet undetermined, possibly between $200,000,000$ to $300,000,000$ per day during the dryest summers, and $2,000,000,000$ or $3,000,000,000$ or more during times of floor.

4. The daily flow, with the river at an average height, may be called 1,000,000,000 gallons; wore than nine-tenths of which, say $900,000,000$, must flow over the Falls of Paterson. The whole discharge of this ricer is $2 \cdot 7$ times that of the Croton River, which supplies New York.

5. The water belongz naturally to the class known as "peaty" waters, though not largely imbued with this contamination, at least, in the lower part of its course.

(6. From the Falls down to the mouth, the peaty matter gradually diminishes in amount.

7. The water is alkaline in character, or at least has a considerable excess of basic over acid constituents. The amounts of lime and magnesia vary at times, but do not differ much from the average of the Croton water.

8. In the lower part of its course, at least, the river contains in solution quantities of nitrates, sufficient to be easily and accurately determined by delicate chemical analysis.

9. These nitrates are increased in quantity by flowing through the city of Paterson, and again nearly doubled by flowing through Newark.

10. These (or their nitric acid) are derived from the oxidation of the animal excretions and other similar refuse that pass into the river at Newark, Paterson and elsewhere, from sewers, slaughterhouses and other sources; materials that would otherwise remain in the water in a state of putrefaction. 
11. There is no reason to believe that these nitrates affect health in any way whatever.

12. The oxidizing power of this alkaline river water, in the autumn season, is so great, that but slight traces of the sewer-matter can be detected, after flowing but four miles through the channel; so little being left that the water acquires no odor un being kept in a closed bottle at $60^{\circ} \mathrm{F}$. for one month.

13. There are as yet no results on record in the way of testy during the summer season, when the water absorbs much less oxygen.

14. This water allows the germination, and supports the growth, of green confervoid vegetation in its bosom, under favorable circumstances, until after it has passed through the city of Newark, when it loses this power; losing some of its constituents at the same time, while gaining others, and changing materially in composition.

15. In the opinion of the undersigned, it will not be safe to have sewers from the city of Newark, at any season, discharge into the river nearer to the pumping works than they do at present; unless the water is conducted to the pumps from a point correspondingly further up the river.

16. This latter precaution is suggested for adoption at once, so long as the present pumping stations are adhered to.

17. It is suggested also that the practicability be examined into, by the Engineer of your Board, of keeping the water, in at least one of the reservoirs, during the summer months at least, in a condition of slow intestinal motion or agitation, in order to promote absorption of oxygen, and consequent destruction of organic impurities.

18. No metallic or mineral poison can be detected, as cast into the stream at Paterson; nor could any such remain in solution therein for any length of time.

All of which is respectfully submitted.

The St. Gothard Tunnel.-The total extent of advance in this undertaking, at the end of March last, was 806.4 feet. About 800 workmen are employed. Considerable trouble is at present being suffered on account of the flow of water into the workings through the micaceous rock, which at one time amounted to seventy-five quarts per second, and greatly delayed the progress of the work. 